\title{
Design of Novel High-Strength Bainitic Steels
}

\author{
F. G. Caballero* and H. K. D. H. Bhadeshia** \\ *Department of Physical Metallurgy, Centro Nacional de Investigaciones Metalúrgicas \\ (CENIM), Consejo Superior de Investigaciones Científicas (CSIC), Avda. Gregorio del \\ Amo, 8, 28040 Madrid, Spain. \\ **Department of Materials Science and Metallurgy, University of Cambridge, Pembroke \\ Street, Cambridge CB2 3QZ, UK.
}

\begin{abstract}
With careful design, mixed microstructures consisting of fine plates of upper bainitic ferrite separated by thin films of stable retained austenite have exhibited impressive combinations of strength and toughness in high-silicon bainitic steels. The silicon suppresses the precipitation of brittle cementite leading to an improvement in toughness. The essential principles governing the optimisation of such microstructures are well established, particularly that large regions of unstable high-carbon retained austenite must be avoided. The aim of the present work was to see how far these concepts can be extended to achieve the highest ever combination of strength and toughness in bulk-samples, consistent with certain hardenability and processing requirements.
\end{abstract}

\section{Introduction}

The thermomechanical control processed bainitic steels have not been in practice as successful as those quenched and tempered, because the presence of coarse cementite particles in the bainitic microstructure. The formation of cementite has a detrimental effect in the microstructure since cementite particles are responsible for damage initiation in modern high-strength steels. However, the precipitation of cementite during bainitic transformation can be suppressed by alloying the steel with about $1.5 \mathrm{wt}-\%$ of silicon, which has very low solubility in cementite and greatly retards its growth from austenite. The carbon that is rejected from the bainitic ferrite enriches the residual austenite, thereby stabilising it down to ambient temperature. The resulting microstructure consists of fine plates of bainitic ferrite separated by carbon-enriched regions of austenite. There may also be some martensite present.

This mixed microstructure is in principle an ideal combination from many points of view. In particular, the steel has a high resistance to cleavage fracture and void formation due to the absence of fine carbides. There is then a possibility of improving simultaneously the strength and toughness because of the ultrafine grain size of the bainitic ferrite plates, and of further enhancing the toughness by a transformation-induced plasticity effect.

In spite of all these potential advantages, the carbide-free bainitic microstructure has on some occasions failed to live up to its promise. This is primarily because of the instability of relatively large or blocky regions of austenite which become trapped between sheaves of bainite. Therefore, every effort has to be made to reduce the fraction of blocky austenite present in the microstructure and increase its stability to martensitic transformation. The aim of alloy design should then be to increase the maximum permitted degree of transformation to bainitic ferrite. There may be other constraints, for example, the need to ensure that the hardenability of the steel is sufficient for avoiding proeutectoid ferrite formation during cooling. 


\title{
Modelling of microstructure and properties
}

\author{
Improvement of toughness, the $T_{o}^{\prime}$ curve
}

The bainite transformation progresses by the diffusionless growth of tiny platelets known as "sub-units". The excess carbon in these platelets partitions into the residual austenite soon after the growth event. Diffusionless growth of this kind can only occur if the carbon concentration of the residual austenite is below that given by the $T_{o}^{\prime}$ curve. The $T_{o}$ curve is the locus of all points, on a temperature versus carbon concentration plot, where austenite and ferrite of the same chemical composition have the same free energy. The $T_{o}^{\prime}$ curve is defined similarly but taking into account the stored energy of the ferrite due to the displacive mechanism of transformation. It follows that the maximum amount of bainite that can be obtained at any temperature is limited by the fact that the carbon content of the residual austenite must not exceed the $T_{o}^{\prime}$ curve on the phase diagram. ${ }^{1-4}$

The $T_{o}^{\prime}$ concept can be used to optimise the mechanical properties by minimising blocky, unstable austenite. ${ }^{5,6}$ An increase in the amount of bainitic ferrite in the microstructure is needed in order to consume the blocks of austenite.

The variation of the carbon content of austenite, $x_{\gamma}$ as a function of the average carbon content of the alloy, $\bar{x}$, and the volume fraction of bainitic ferrite $V_{b}$ is given by, ${ }^{7}$

$$
x_{\gamma}=\bar{x}+V_{b} \frac{(\bar{x}-s)}{\left(1-V_{b}\right)}
$$

where $s$ is the amount of carbon trapped in the bainitic ferrite, either in solid solution $(s=0.03$ wt- $\%)$, or in the form of carbides ( $s=0.27 \mathrm{wt}-\%)$.

Previous work ${ }^{7,1}$ suggested two main methods of increasing the maximum permitted degree of transformation to bainitic ferrite:

- by reducing the overall carbon content $\bar{x}$ of the alloy concerned, so that the critical concentration in the austenite at which displacive transformation becomes impossible is reached at a later stage (and hence a higher $V_{b}$ ) in the transformation (equation (1)). Of course, this is only useful if the reduction of the overall carbon content of the alloy does not at the same time lead to a decrease in the strength of the microstructure.

- by modifying the substitutional alloying elements such that the $T_{o}^{\prime}$ curve is shifted to higher austenite carbon concentrations. ${ }^{7,5,1}$

\section{Time-Temperature-Transformation (TTT) diagrams}

Apart from controlling the $T_{o}^{\prime}$ curve, substitutional solutes also affect hardenability which is an important design parameter since industrial manufacturing generally involves continuous cooling transformation. For this purpose, we use a thermodynamic method ${ }^{8}$ developed to allow the estimation of isothermal transformation diagrams, from a knowledge of the chemical composition of the steel concerned.

The TTT diagram is treated as being composed of two overlapping ' $\mathrm{C}$ ' curves, one representing the diffusional ferrite and pearlite transformations, and the other representing the displacive Widmanstätten ferrite and bainite reactions. It is possible to predict relative shifts 
in these component curves, as a function of alloying element content, thus making the technique potentially useful in the theoretical steel design.

\section{Design of novel bainitic steels}

Previous research, carried out by Bhadeshia and Edmonds ${ }^{5,6}$ and Miihkinen and Edmonds ${ }^{9-11}$, on two silicon-containing steels, nominally, Fe-0.2C-2Si-3Mn wt- $\%$ and Fe-0.4C-2Si-4Ni wt$\%$ showed that these alloys hold promise. The Fe-0.2C-2Si-3Mn wt-\% alloy exhibited excellent fracture toughness $\left(K_{I c}=160 \mathrm{MPa} \sqrt{m}\right)$ in a strength range of $1375-1440 \mathrm{MPa}$ as isothermally heat-treated at $250{ }^{\circ} \mathrm{C}$. This fracture toughness is better or equal than that of quenched and tempered AISI $300 \mathrm{M}$ and AISI 4340 steels at equivalent strength levels and approaches that of the $18 \mathrm{wt}-\% \mathrm{Ni}$ maraging steel. ${ }^{11}$ Because of the increased carbon content, higher strength levels $1500-1840 \mathrm{MPa}$ were obtained in the Fe-0.4C-2Si-4Ni wt-\% alloy, with lower fracture toughness values, but this still exceeded those of commercial high strength martensitic steels. The original experiments ${ }^{5,6}$ were carried out in order to demonstrate the role of the $T_{o}^{\prime}$ curve in greatly influencing the mechanical properties of carbide-free bainitic steels. The experimental alloys developed for this purpose are not necessarily the optimum alloys from the point of view of mechanical properties. Our aim here was to use the combination of the models described above, to produce the best possible alloys, with microstructures produced by continuous cooling transformation, building on the previous work. ${ }^{5,6}$

Using the models together with some background knowledge, the following modifications were proposed to increase the maximum volume fraction of bainite in the final microstructure and to improve the hardenability of the steels:

- The silicon content was reduced to what is believed to be the minimum $(1.5 \mathrm{wt}-\% \mathrm{Si})$ required to suppress carbide precipitation. This should lead to an improvement in the impact toughness, without deterioration in the $T_{o}^{\prime}$ criterion or the hardenability.

- With the aim of increasing the strength of the Fe-0.2C-2Si-3Mn wt- $\%$ alloy, the carbon content was increased to $0.3 \mathrm{wt}-\% \mathrm{C}$ with a reduction in the $\mathrm{Mn}$ content to $2 \mathrm{wt}-\% \mathrm{Mn}$ in order to retain toughness. It was found that the $T_{o}^{\prime}$ curve shifts to higher carbon when the $\mathrm{Mn}$ content is reduced. However, a reduction in manganese naturally reduces hardenability.

- In order to increase toughness of the Fe-0.4C-2Si-4Ni wt-\% alloy, the amount of carbon was reduced to $0.3 \mathrm{wt}-\% \mathrm{C}$. Calculations show that the hardenability did not seem to change appreciably.

- Substantial improvements in both the strength and hardenability were obtained by adding $1.44 \mathrm{wt}-\% \mathrm{Cr}$ to the nickel alloy. However, the $T_{o}^{\prime}$ curve was found to shift to much lower carbon concentrations. Finally, Ni was reduced to $3.5 \mathrm{wt}-\% \mathrm{Ni}$ to increase the residual austenite carbon content without significantly sacrificing hardenability. For the manganese alloy, the best hardenability was achieved by adding $1.30 \mathrm{wt}-\% \mathrm{Cr}$ without changes in Mn content.

- Commercial alloys inevitably contain phosphorus and other impurities. An addition of $0.25 \mathrm{wt}-\%$ Mo was made to reduce impurity embrittlement and to increase hardenability. This addition shifted the $T_{o}^{\prime}$ curve to lower austenite carbon concentrations and hence the molybdenum was limited to $0.25 \mathrm{wt}-\%$. 
- Vanadium was added to restrict austenite grain growth during the austenitising heat treatment.

The alloys that have been proposed following a very large number of theoretical investigations, are listed in Table 1. Their compositions are expressed in weight percent. Figure 1 shows the calculated TTT diagrams representing the initiation of transformation. Also plotted are representative cooling curves ${ }^{12}$ simply as an indication of hardenability. The curves should really be plotted on continuous cooling transformation diagrams, where the transformation curves would be displaced to longer times. The calculated microstructures listed in Fig. 1 are, on the other hand, rigorous, using the methods described in Refs. 13 and 14. In order to form a mixed microstructure of bainite and austenite by continuous cooling, it is necessary to avoid polygonal-ferrite and pearlite transformations. The diagrams suggest that the Ni1 and Ni2 alloys have enough hardenability if the steel is cooled in oil. In that case, the final microstructure in both steels is predicted to be 0.89 bainite and 0.11 austenite. Due to the high degree of transformation to bainite that takes place, the majority of the retained austenite is expected to be present as films between the sub-units of bainitic ferrite. This should result in a microstructure with an optimum toughness. Furthermore, for the Mn alloy, a bainite-rich microstructure can be obtained by air cooling, but it is possible that some polygonal-ferrite may form. However, because of the slow kinetics at temperatures as low as $600{ }^{\circ} \mathrm{C}$, it is likely that any polygonal-ferrite will be very limited.

\section{Experimental procedure}

The actual chemical compositions of the steels studied are given in Table 2. Alloys were prepared as $35 \mathrm{~kg}$ vacuum induction melts using high purity base materials. After casting and cropping, the ingots were hot forged down to a thickness of $65 \mathrm{~mm}$. These were then homogenised at $1200{ }^{\circ} \mathrm{C}$ for 2 days and cut into smaller $65 \mathrm{~mm}$ thick samples which were then forged down to $50 \mathrm{~mm}$ thickness. These samples were then held at $900^{\circ} \mathrm{C}$ for 2 hours, removed from the furnace and immediately hot-pressed to a thickness of $25 \mathrm{~mm}$ before their temperature fell below $750{ }^{\circ} \mathrm{C}$. Finally they were allowed to cool in air.

Quantitative X-ray analysis was used to determined the fraction of retained austenite. For this purpose, samples were cut from undeformed regions of Charpy specimens. After grinding and final polishing using $0.25 \mu \mathrm{m}$ diamond paste, the samples were etched to obtain an undeformed surface. They were then step-scanned in a Philips - PW 1730 X-ray

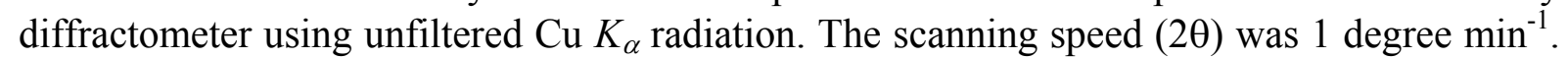
The machine was operated at $40 \mathrm{kV}$ and $40 \mathrm{~mA}$. The retained austenite content was calculated from the integrated intensities of (200), (220) and (311) austenite peaks, and those of (002), (112) and (022) planes of ferrite. ${ }^{15}$ Using three peaks from each phase avoids biasing the results due to any crystallographic texture in the samples. ${ }^{16}$ The carbon concentration in the austenite was estimated by using the lattice parameters of the retained austenite. ${ }^{17}$

Specimens for transmission electron microscopy (TEM) were machined down to $3 \mathrm{~mm}$ diameter rod. The rods were sliced into $100 \mu \mathrm{m}$ thick discs and subsequently ground down to foils of $50 \mu \mathrm{m}$ thickness on wet 800 grit silicon carbide paper. These foils were finally electropolished at room temperature until perforation occurred, using a twin-jet electropolisher set at a voltage of $40 \mathrm{~V}$. The electrolyte consisted of $5 \%$ perchloric acid, $15 \%$ glycerol and $80 \%$ methanol. The foils were examined in a JEOL JEM-200 CX transmission electron microscope at an operating voltage of $200 \mathrm{kV}$.

Optical and scanning electron microscopy (SEM) were used to examine the etched microstructures. Specimens were polished in the usual way and etched in $2 \%$ Nital solution, 
and examined using a JEOL JXA-820 scanning electron microscope operated at 10-15 kV. The volume fraction of bainite $\left(V_{b}\right)$ was estimated by a systematic manual point-counting procedure on scanning electron micrographs. ${ }^{18}$ A grid superimposed on the microstructure provides, after a suitable number of placements, an unbiased statistical estimate of $V_{b}$.

Tensile testing was carried out in accordance with BS EN 10 002-1: 1990 at room temperature on a $100 \mathrm{kN}$ Instron- 6025 machine at a crosshead speed of $2 \mathrm{~mm} \mathrm{~min}^{-1}$. Two specimens were tested for each alloy.

Impact toughness was measured at temperatures between 20 and $-120{ }^{\circ} \mathrm{C}$ using a $300 \mathrm{~J}$ Charpy testing machine. Specimens were tested in accordance with BS EN 10 045-1: 1990. Six specimens were tested at each temperature for every alloy.

Compact tension specimens were used to measure values of plane strain fracture toughness $\left(K_{I c}\right)$ at room temperature for the Ni1 and Ni2 alloys in accordance with BS 7448 Part1: 1991. Compact tension / fracture toughness testing was done on a $100 \mathrm{kN}$ ESH servohydraulic machine. The crosshead speed used was $1 \mathrm{~mm} \mathrm{~min}^{-1}$.

Fractography was carried on the Charpy impact toughness specimens using a JEOL JXA-820 scanning electron microscope operating at $20 \mathrm{kV}$.

\section{Results and discussion}

\section{Characterisation of microstructure}

Experimental data of the designed steel microstructures are presented in Table 3. These data and the micrographs presented in Fig. 2 reveal that Ni1 and Ni2 have the desired microstructure consisting of mainly bainitic ferrite and retained austenite. Because of the high carbon content in austenite $\left(x_{\gamma}\right)$ for these alloys (Table 3 ), the majority of residual austenite present after bainite is formed, is retained on cooling to room temperature. In the SEM micrographs martensite regions are relatively unetched, and appear light in colour. The thin interlath films of austenite, however, have been etched away. It is difficult in thin-foil TEM experiments to judge whether any martensite has formed as a result of the thinning process or whether it was present in the original microstructure. To cope with this, the samples were tempered at $200{ }^{\circ} \mathrm{C}$ for $2 \mathrm{~h}$ before making foils. Thus, martensite present in the original sample would contain carbides, whereas any untempered martensite can be interpreted to be austenite which underwent transformation during the foil preparation process. The observation of tempered microstructures (Fig. 2.c) showed that the unetched regions in Fig $2 . \mathrm{b}$ are martensitic. Note that the low temperature tempering $\left(200{ }^{\circ} \mathrm{C}\right)$ heat treatment does not affect bainitic ferrite since the latter does not contain excess carbon.

Due to the high volume fraction of bainitic ferrite in Ni1 and Ni2 alloys, 0.62 and 0.81 respectively, the retained austenite was largely present as films between the subunits of bainitic ferrite. Figure 3 shows typical bright-field images of carbide-free upper bainite in Ni1 and Ni2 with interlath retained austenite films. These films have a typical wavy morphology characteristic of the bainite in high-silicon steels (Fig. 3.b). ${ }^{9-11,19}$

By contrast, the small amount of bainite in the Mn alloy (Table 3) causes much of the residual austenite to transform to martensite during cooling because of lower carbon-enrichment of the austenite $(0.55 \mathrm{wt}-\%$, Table 3$)$. There is only $10 \%$ of the residual austenite retained to room temperature $\left(V_{\gamma}=0.07\right.$, Table 3$)$. These results are consistent with the data on instability of residual austenite as function of austenite carbon content illustrated elsewhere. ${ }^{5}$

The results of hardness tests are presented in Table 4. There is no doubt that the microstructures of Ni1 and Ni2 alloys in the as-received condition consist mainly of bainite and retained austenite. Their hardness values are closer to those of microstructures obtained 
isothermally at $375^{\circ} \mathrm{C}$ than the respective hardness values of the martensite as determined by water quenched following austenitisation at $1000{ }^{\circ} \mathrm{C}$ for $15 \mathrm{~min}$. Any difference between the hardness values of as-received and isothermally transformed microstructures in Ni1 and $\mathrm{Ni} 2$ alloys is due to the different degree of transformation to bainitic ferrite. Not surprisingly, the hardness value for the as-received microstructure of Mn alloy (Fig. 2.a) is similar to that of a fully martensitic sample.

\section{Mechanical properties}

Tensile test results are presented in Table 5. Plates of bainitic ferrite are typically $10 \mu \mathrm{m}$ in length and about $0.2 \mu \mathrm{m}$ in thickness (Fig. 3). This gives a rather small mean free path for dislocation glide. Thus, the main microstructural contribution to the strength of bainite is from the extremely fine grain size of bainitic ferrite. ${ }^{20}$

It is difficult to separate the effect of retained austenite on strength in these steels from other factors. Qualitatively, austenite can affect the strength in several ways. Residual austenite can transform to martensite during cooling to room temperature, thus increasing the strength as observed in Mn alloy (Tables 3 and 5). On the other hand, retained austenite interlath films can increase the strength by transforming to martensite during testing, similar to the behaviour of TRIP (transformation induced plasticity) steels.

The low yield/ultimate tensile strength ratios (YS/UTS) in Table 5 are due to the presence of austenite and the generally large dislocation density in the microstructure. ${ }^{21}$ Consequently, retained austenite increases the strain-hardening rate of the steel. Likewise, tensile elongation is controlled by the volume fraction of retained austenite. ${ }^{22}$ Retained austenite is a ductile phase compared to the bainitic ferrite and would be expected to enhance ductility as far as the austenite is homogeneously distributed along plate boundaries (film austenite). However, isolated pools of austenite (blocky austenite) would influence unfavourably on both elongation and UTS. From Table 5, it is clear that the steels present a combination of high strength and good ductility.

Charpy impact test results are listed in Table 6 for all the alloys. A considerable improvement in toughness is obtained when the volume fraction of bainite increases in the microstructure. This improvement occurs despite the fact that the strength of the microstructures involved remains almost unchanged (Table 5). From the data in Table 3, it is evident that the volume fraction of bainite $V_{b}$ and thus the carbon content of the retained austenite $x_{\gamma}$ explains the improvement in toughness observed in Ni1 and Ni2 alloys as compared with the Mn alloy. The results are consistent with the enhancement of toughness expected when the amount of blocky austenite and martensite are reduced and, in general, when the stability of residual austenite is increased. Figure 4 shows the fracture surfaces of the Charpy impact specimens tested at room temperature. The two Ni alloys show ductile dimpled fracture surfaces whereas the Mn alloy, which contains a large amount of martensite, has many of the features of quasicleavage with isolated patches of ductile fracture.

A compact tension specimen design was used with thickness $B=23.1 \mathrm{~mm}$, width $\mathrm{W}=46.5 \mathrm{~mm}$, and crack length, $\mathrm{a}=24.5 \mathrm{~mm}$, to width ratio of $\mathrm{a} / \mathrm{W}=0.5$. With the measured yield stress of $1100 \mathrm{MPa}$, this would give a plane strain, $K_{I c}$, measurement capacity of $\sim 300 \mathrm{MPa} \sqrt{m}$. In the event, none of the specimens failed at sufficiently low load to satisfy the $K_{I c}$ validity requirement.

The specimens showed a fairly significant non-linearity before maximum load. This disqualified the use of $K_{Q}$ as a $K_{I c}$ measurement. The values quoted in Table 5 are for the stress intensity at maximum load, $K_{\max }$. All the tests failed by microvoid coalescence with no sign of cleavage. Tearing was stable at maximum load under displacement control. Taking 
account of the non-linearity in the trace up to maximum load gives the $J$-Integral at maximum load, $J_{\max }$ and the stress intensity $K_{J_{\max }}$ calculated from $J_{\max }$ values listed in Table 5.

Although the obtained fracture toughness results can not be considered valid, the results are promising in that the steels tested are so tough that larger samples would be needed to measure $K_{I c}$. Toughness values of nearly $130 \mathrm{MPa} \sqrt{m}$ have been obtained for strength in the range of 1600-1700 MPa. The good fracture toughness obtained in these alloys is attributed to the presence of thin films of thermally and mechanically stable interlath retained austenite. The role of retained austenite is to refine the effective fracture grain size and to a blunt propagating crack. $^{6}$

Figure 5 shows properties of mixed microstructures of bainitic ferrite and austenite, versus those of quenched and tempered (QT) low-alloy martensitic alloys and maraging steels. ${ }^{7}$ Small points in the graph refer to previous work, ${ }^{5-8,12}$ whereas the two large points correspond to experimental data shown in Table 5. The alloys designed theoretically in this work and produced by commercial continuous cooling present the highest strength/toughness combinations ever recorded in bainitic steels. These alloys show better mechanical properties of the QT low-alloy martensitic alloys and match the critical properties of maraging steels, which are at least thirty times more expensive.

\section{Conclusions}

It has been demonstrated experimentally that models based on phase transformation theory can be applied successfully to the design of high strength and tough steels. These alloys designed to ensure that the hardenability of the steel is sufficient for industrial production have achieved the highest strength and toughness combinations to date for bainitic steels, at a cost thirty times less than that of maraging steels.

\section{Acknowledgments}

The authors would like to thank to Professor Alan Windle for the provision of laboratory facilities at the University of Cambridge. F.G. Caballero would like to thank Spanish Ministerio de Ciencia y Tecnología for the financial support in the form of a Ramón y Cajal contract (Programa RyC 2002).

\section{Referentes}

1. H. K. D. H. BHADESHIA: Acta Metall., 1981, 29, 1117-1130.

2. H. K. D. H. BHADESHIA and A. R. WAUGH: Acta Metall., 1982, 30, 775-784.

3. L. C. CHANG and H. K .D. H. BHADESHIA: Mater. Sci. Eng., 1994, A184, L17-20.

4. I. STARK, G. D. W. SMITH and H. K. D. H. BHADESHIA: in 'Solid $\rightarrow$ Solid Phase Transformations', (ed. G. W. Lorimer), 211-215; 1988, London, Institute of Metals.

5. H. K. D. H. BHADESHIA and D. V. EDMONDS: Metal Sci., 1983, 17, , 411-419.

6. H. K. D. H. BHADESHIA and D. V. EDMONDS: Metal Sci., 1983, 17, 420-425.

7. H. K. D. H. BHADESHIA and D. V. EDMONDS: Acta Metall., 1980, 28, 1265-1273.

8. H. K. D. H. BHADESHIA: Metal Sci., 1982, 16, 159-165.

9. V. T. T. MIIHKINEN and D. V. EDMONDS: Mater. Sci. Technol., 1987, 3, 422-431.

10. V. T. T. MIIHKINEN and D. V. EDMONDS: Mater. Sci. Technol., 1987, 3, 432-440.

11. V. T. T. MIIHKINEN and D. V. EDMONDS: Mater. Sci. Technol., 1987, 3, 441-449.

12. Defence Evaluation Research Agency Technical Note, DRA/WSS/WT6/CR/93 2/1.0. 
13. N. CHESTER and H. K. D. H. BHADESHIA: Journal de Physique IV, 1997, 7, 41-46.

14. S. J. JONES and H. K. D. H. BHADESHIA: Acta Materialia, 1997, 45, 2911-2920.

15. J. DURNIN and K. A. RIDAL: Journal of the Iron and Steel Institute, 1968, 206, 60.

16. M. J. DICKSON: J. Appl. Cryst., 1969, 2, 176-180.

17. D. J. DYSON and B. HOLMES: Journal of the Iron and Steel Institute, 1970, 208, 469.

18. G. F. VANDER VOORT: 'Metallography. Principles and Practice', 427; 1984, New York, McGraw-Hill.

19. L. C. CHANG: Metall. Trans., 1999, 30A, 909-916.

20. K. J. IRVINE, F. B. PICKERING, W. C. HESELWOOD and M. J. ATKINS: J. iron Steel Inst., 1957, 195, 54-67.

21. A. P. COLDREN, R. L. CRYDERMAN and M. SEMCHYSHEN: 'Steel Strengthening Mechanisms', 17; 1969, Ann Arbor, USA, Climax Molybdenum.

22. B. P. J. SANDVIK and H. P. NEVALAINEN: Met. Tech., 1981, 15, 213-220. 
Table 1.- Chemical Composition of Alloys Designed, wt- $\%$

\begin{tabular}{cccccccc}
\hline Alloy & $\mathrm{C}$ & $\mathrm{Si}$ & $\mathrm{Mn}$ & $\mathrm{Ni}$ & $\mathrm{Cr}$ & $\mathrm{Mo}$ & $\mathrm{V}$ \\
\hline $\mathrm{Mn}$ & 0.30 & 1.5 & 2.00 & - & 1.30 & 0.25 & 0.1 \\
$\mathrm{Ni} 1$ & 0.30 & 1.5 & - & 3.5 & 1.44 & 0.25 & 0.1 \\
$\mathrm{Ni} 2$ & 0.30 & 1.5 & - & 3.5 & 1.44 & 0.25 & - \\
\hline
\end{tabular}


Table 2.- Actual Chemical Composition of Designed Alloys, wt- $\%$

\begin{tabular}{cccccccc}
\hline Alloy & $\mathrm{C}$ & $\mathrm{Si}$ & $\mathrm{Mn}$ & $\mathrm{Ni}$ & $\mathrm{Cr}$ & $\mathrm{Mo}$ & $\mathrm{V}$ \\
\hline $\mathrm{Mn}$ & 0.32 & 1.45 & 1.97 & $<0.02$ & 1.26 & 0.26 & 0.10 \\
$\mathrm{Ni} 1$ & 0.31 & 1.51 & $<0.01$ & 3.52 & 1.44 & 0.25 & 0.10 \\
$\mathrm{Ni} 2$ & 0.30 & 1.51 & $<0.01$ & 3.53 & 1.42 & 0.25 & $<0.005$ \\
\hline
\end{tabular}


Table 3.- Quantitative Data on Microstructure and Hardness*

\begin{tabular}{cccccc}
\hline Alloy & $V_{b}$ & $V_{\gamma}$ & $V_{\alpha^{\prime}}$ & $x_{\gamma}, \mathrm{wt}-\%$ & Hardness, HV30 \\
\hline Mn & $0.26 \pm 0.01$ & $0.07 \pm 0.01$ & $0.67 \pm 0.02$ & 0.55 & $597 \pm 2$ \\
$\mathrm{Ni} 1$ & $0.62 \pm 0.05$ & $0.12 \pm 0.01$ & $0.26 \pm 0.04$ & 0.92 & $493 \pm 5$ \\
$\mathrm{Ni} 2$ & $0.81 \pm 0.06$ & $0.11 \pm 0.01$ & $0.08 \pm 0.05$ & 1.03 & $536 \pm 6$ \\
\hline $\begin{array}{l}V_{b} \text { bainitic ferrite volume fraction; } V_{\gamma} \text { retained austenite volume fraction; } V_{\alpha^{\prime}} \\
\text { martensite volume fraction; } x_{\gamma} \text { carbon content in austenite }\end{array}$ &
\end{tabular}


Table 4.- Hardness Data of Different Microstructures of the Alloys Studied

\begin{tabular}{lll}
\hline Alloy & Heat treatment & Hardn \\
\hline $\mathrm{Mn}$ & & \\
& & \\
& As received microstructure & $597 \pm 2$ \\
& $\mathrm{WQ}^{\dagger}$ & $605 \pm 5$ \\
& $350^{\circ} \mathrm{C}$ for $30 \mathrm{~min}, \mathrm{WQ}$ & $467 \pm 7$
\end{tabular}

Ni1

As received microstructure

$493 \pm 5$

WQ

$647 \pm 8$

$375^{\circ} \mathrm{C}$ for $30 \mathrm{~min}$, WQ

$426 \pm 4$

$\mathrm{Ni} 2$

As received microstructure

$536 \pm 6$

WQ

$669 \pm 7$

$375{ }^{\circ} \mathrm{C}$ for $30 \mathrm{~min}$, WQ

$423 \pm 9$

*Hardness values are averaged over 10 tests

$\dagger$ WQ water quench 
Table 5.- Tensile* and Fracture Toughness ${ }^{\dagger}$ Properties

\begin{tabular}{llllllll}
\hline Alloy & $\begin{array}{l}\text { YS } \\
\text { MPa }\end{array}$ & $\begin{array}{l}\text { UTS } \\
\text { MPa }\end{array}$ & $\begin{array}{l}\text { Elongation } \\
\%\end{array}$ & $\begin{array}{l}\text { RA } \\
\%\end{array}$ & $\begin{array}{l}K_{\max } \\
\mathrm{MPa} \sqrt{m}\end{array}$ & $\begin{array}{l}J_{\max } \\
\mathrm{MPa} m\end{array}$ & $\begin{array}{l}K_{\max } \\
\mathrm{MPa} \sqrt{m}\end{array}$ \\
\hline Mn & 1167 & 1790 & 13 & 44 & & & \\
$\mathrm{Ni} 1$ & 1150 & 1725 & 14 & 55 & 125 & 0.114 & 160 \\
$\mathrm{Ni2}$ & 1100 & 1625 & 14 & 59 & 128 & 0.134 & 174 \\
\hline
\end{tabular}

*YS yield strength; UTS ultimate tensile strength; RA reduction of area.

${ }^{\dagger} K_{\max }$ stress intensity factor at maximum load; $J_{\max } \mathrm{J}$-integral at maximum load;

$K_{J \max }$ stress intensity values calculated from $J_{\max }$ values. 
Table 6.- Charpy Impact Test Results*

\begin{tabular}{lll}
\hline Alloy & Test temperature, ${ }^{\circ} \mathrm{C}$ & Impact energy, $\mathrm{J}$ \\
\hline Mn & 20 & $34 \pm 1$ \\
& -40 & $31 \pm 1$ \\
Ni1 & 20 & $58 \pm 2$ \\
& -40 & $46 \pm 1$ \\
& -120 & $34 \pm 2$ \\
Ni2 & 20 & $50 \pm 3$ \\
& -40 & $43 \pm 1$ \\
& -120 & $25 \pm 3$ \\
\hline
\end{tabular}

*Each value is a mean of six tests 

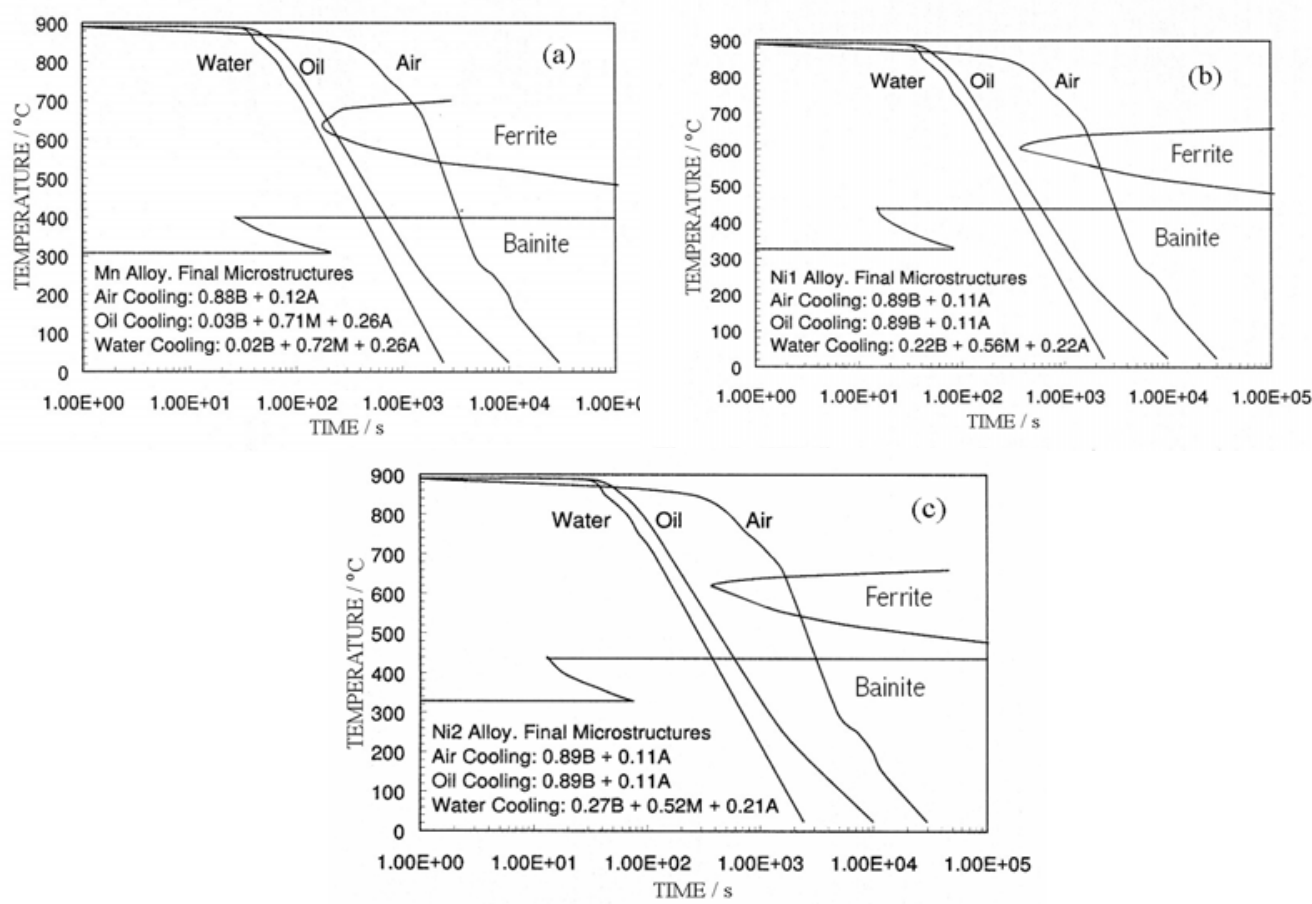

Figure 1.- Calculated TTT diagram for the initiation of transformation. The cooling curves are representative of the core of a steel bar of $210 \mathrm{~mm}$ diameter. They are superimposed on the TTT diagram simply as a rough indication of hardenability. a) Mn alloy; b) Ni1 alloy; c) Ni2 alloy. The legends B, M and A refer to bainite, martensite and austenite, respectively. 


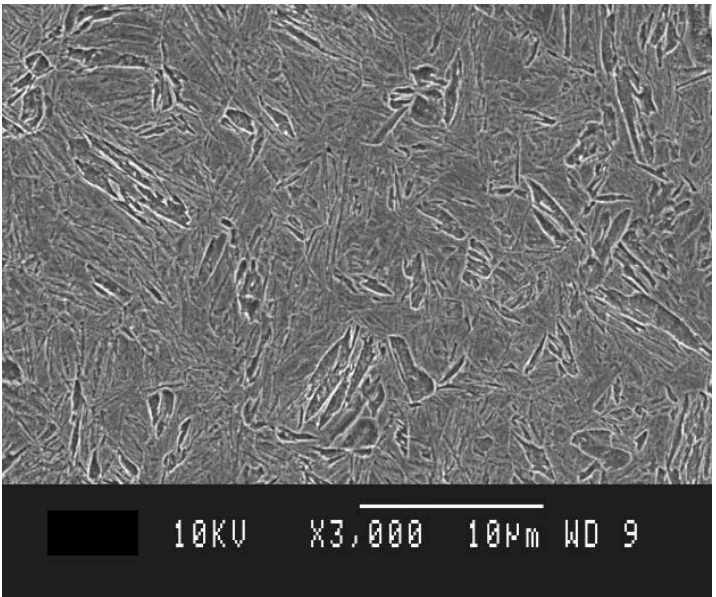

a)

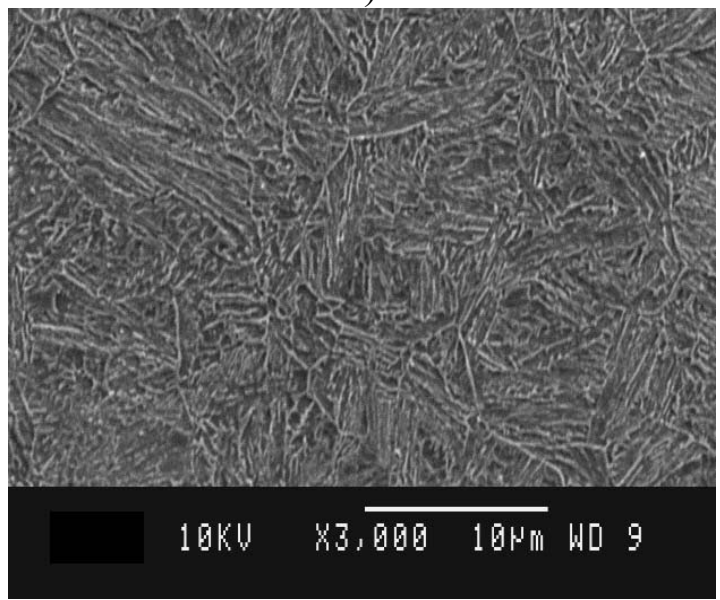

c)

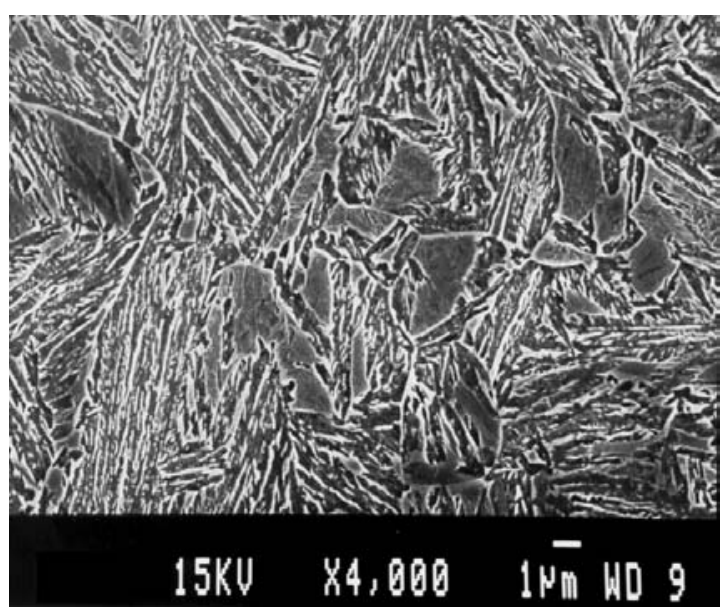

b)

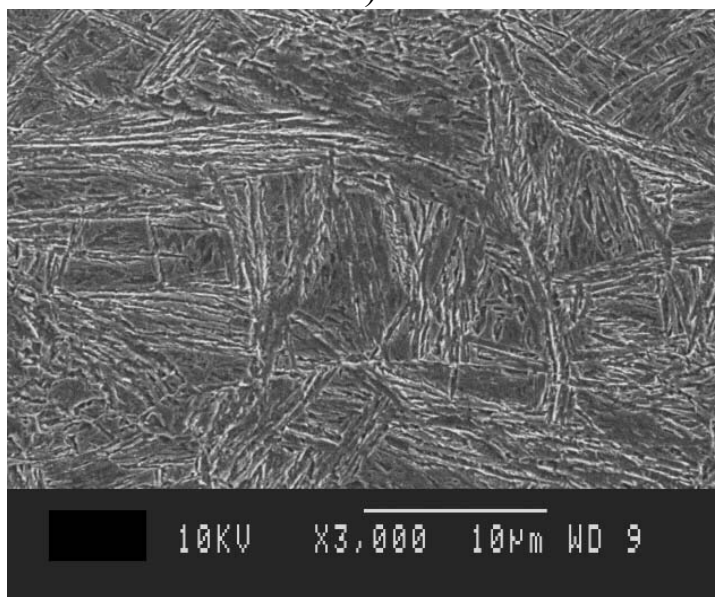

d)

Figure 2.- Scanning electron micrographs of microstructures in the designed alloys: a) Mn alloy as received microstructure; b) Ni1 alloy as received microstructure; c) Ni1 alloy as tempering at $200{ }^{\circ} \mathrm{C}$ for $2 \mathrm{hrs}$. microstructure; d) $\mathrm{Ni} 2$ alloy as received microstructure. 


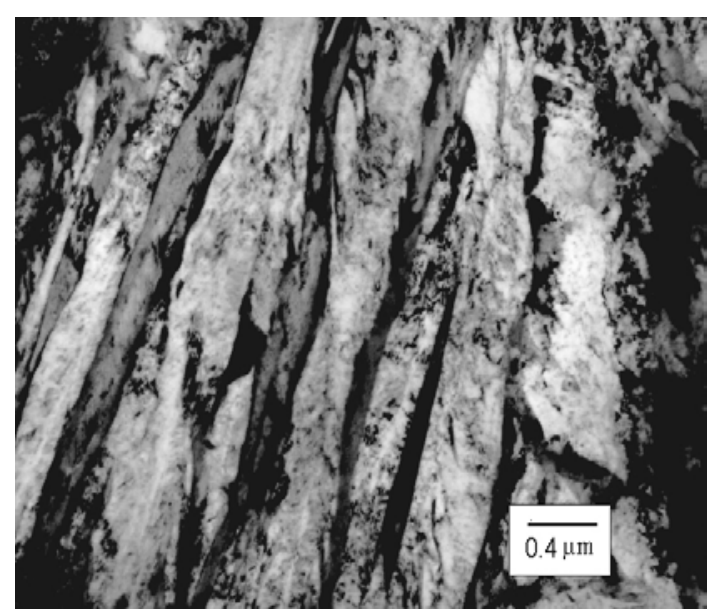

a)

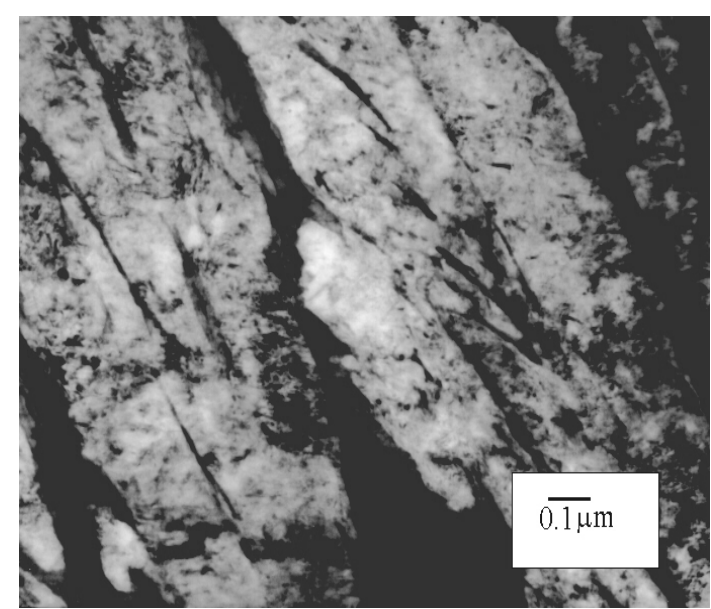

b)

Figure 3.- Typical bright field images of microstructures formed by bainitic ferrite and films of retained austenite: a) Ni1 alloy; b) Ni2 alloy 


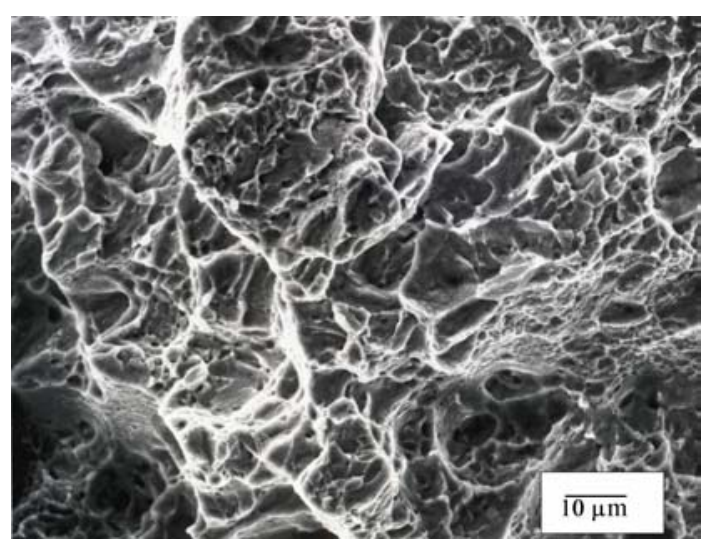

a)

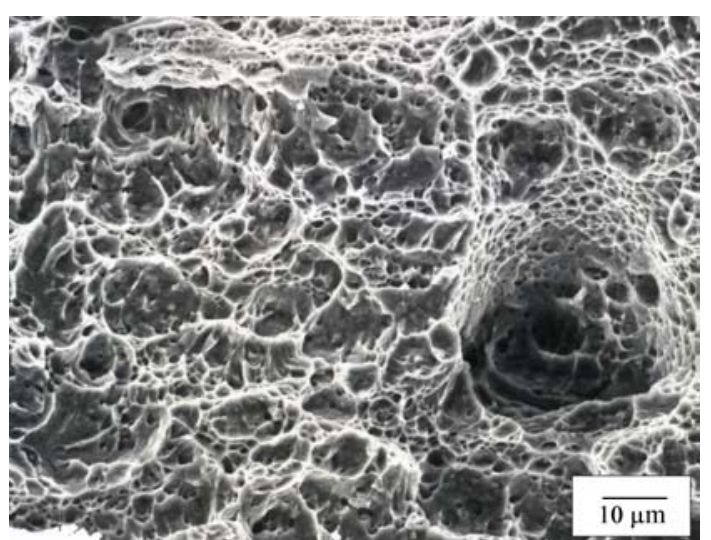

b)

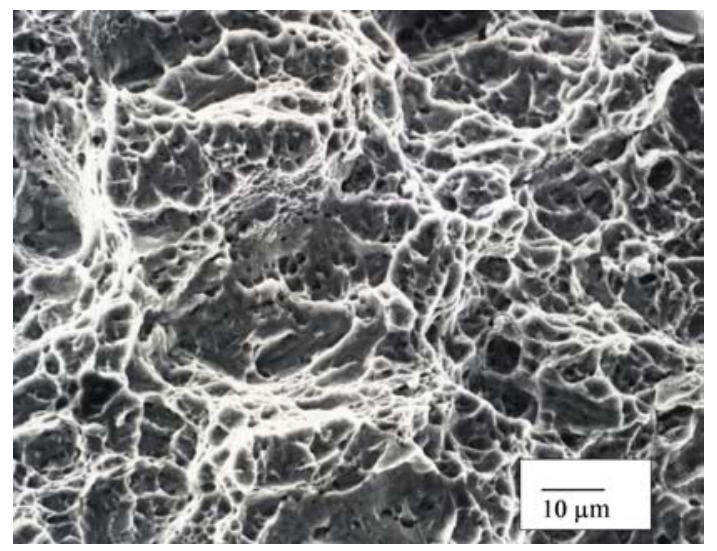

c)

Figure 4.- Fracture surfaces of Charpy impact specimens tested at room temperature. Scanning electron micrographs: a) Mn alloy; b) Ni1 alloy; c) Ni2 alloy. 


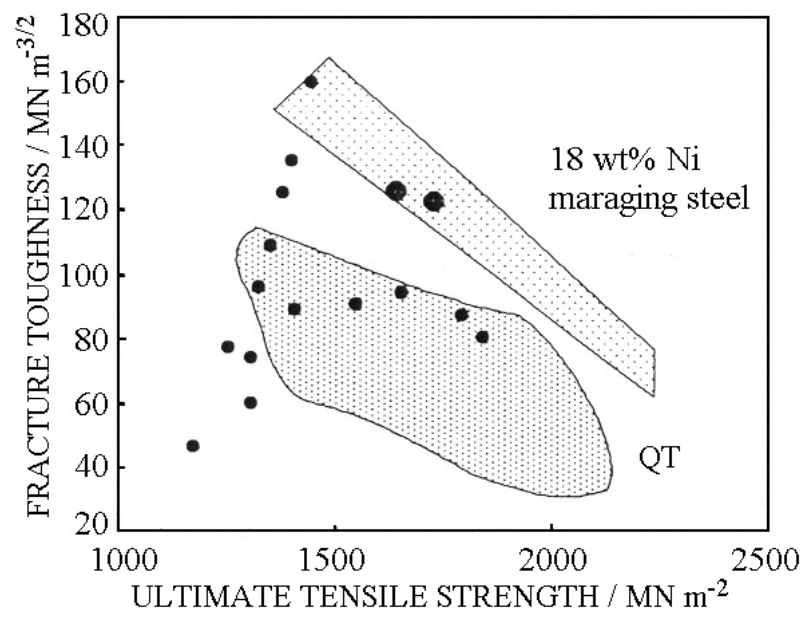

Figure 5.- Properties of mixed microstructures of bainitic ferrite and austenite, versus those of quenched and tempered (QT) low-alloy martensitic alloys and maraging steels. 